Int. J. Electrochem. Sci., 12 (2017) 10095 - 10106

\title{
A Novel Electrochemical Sensor Based on a Graphene-Silver Platform for the Sensitive Determination of a Tumor-Supplied Group of Factors
}

\author{
Yan Zhang ${ }^{1^{*}}$ and Guohong $\mathrm{Li}^{2}$ \\ ${ }^{1}$ Department of Neurology, Yinan County People's Hospital, Shandong, 276300, P.R. China \\ ${ }^{2}$ Department of Laboratory, Dezhou Municipal Hospital, No. 1766 Middle Sanba Rd, Decheng, \\ Dezhou, Shandong, 253012, P.R. China \\ *Corresponding author: Yan Zhang E-mail: Lghhappy111@ sina.com
}

doi: $10.20964 / 2017.11 .13$

Received: 8 July 2017 / Accepted: 26 August 2017 / Published: 12 October 2017

\begin{abstract}
This work reported the facile fabrication of a silver nanoparticle (AgNP)/graphene oxide (GO)-based nanocomposite with glucose as a reducing and stabilization agent using an eco-friendly and low-cost method. The synthetic process could be conveniently employed in the fabrication of a disposable electrochemical sensor using a glassy carbon electrode (GCE). Based on the experimental results, this nanocomposite displayed the integrated properties of graphene and silver nanoparticles, which significantly promoted its electrocatalytic behavior. The electrochemical features of the AgNPs/GO/GCE with the tumor-supplied group of factors (TSGF) was evaluated by differential pulse voltammetry (DPV) and cyclic voltammetry (CV). Compared with the GO film, the AgNPs/GO film displayed an obviously higher activity for TSGF electro-oxidation with a tenfold enhancement in the peak current. Under the selected test conditions, the oxidation peak currents were found to be proportional to the concentration of TSGF within the ranges of $0.01 \mu \mathrm{M}-50.0 \mu \mathrm{M}$ and $50.0 \mu \mathrm{M}$ $800.0 \mu \mathrm{M}$. The developed sensor was used for the detection of TSGF in real specimens and showed desirable recoveries in the range of $98.18 \%-102.52 \%$.
\end{abstract}

Keywords: Silver; Graphene; Tumor supplied group of factors; Electrochemical sensor; Human serum

\section{$\underline{\text { FULL TEXT }}$}

(C) 2017 The Authors. Published by ESG (www.electrochemsci.org). This article is an open access article distributed under the terms and conditions of the Creative Commons Attribution license (http://creativecommons.org/licenses/by/4.0/). 